\title{
Finite element non-linear analysis of concrete structures
}

\author{
D. V. PHILLIPS \& O. C. ZIENKIEWICZ
}

\section{Mr I. Davidson, $F$}

The analysis of non-linear structures demands an iterative solution, as stated by the Authors. In such particular cases there are some advantages to an engineer in using a dynamic relaxation process, because this is iterative in any case. Perhaps the main advantage is that the method is exceedingly simple, completely avoiding matrix algebra, and demanding only an elementary knowledge of mathematics and computer programming. A further advantage when analysing cracked structures is that each major crack can be modelled by two new boundary surfaces, permitting the calculation of the position, extent and width of each crack.

83. The latter information is valuable in determining crack extent. The Authors adopt a concrete constitutive law which establishes or extends a crack when a limiting tensile stress or strain is exceeded, but in the presence of the singularity at the tip of the crack, and in an area where the stress-strain relations are no longer linear, it is difficult to attach any specific meaning to the calculated stresses. The alternative approach, in which the width of the crack near the tip is calculated, permits one to use the criterion of crack opening displacement, as in fracture mechanics. This elegant method has been found to give results which agree well with experiments.

84. Very simple dynamic relaxation programs have been written for plane and axisymmetric structures, which are capable of duplicating the calculations described in the Paper. A simple program has also been written for fully three-dimensional structures, in cylindrical co-ordinates. ${ }^{27}$ This was used to analyse a model of a multi-cavity prestressed concrete reactor vessel, and good agreement was obtained with experimental results in linear and non-linear conditions. Such programs allow a good representation of the actual structure, are very versatile and are economical in computer time, while remaining simple.

\section{Dr Y. Bangash, Division of Structures, Thames Polytechnic}

The Authors have made a good attempt to define the mechanics of failure of concrete and to establish a refined criterion for its failure under a complex state of stress. Although they recognize concrete as a redundant structure carrying loads even when cracks have extended through the mortar mix, advances in the use of prestressing techniques for concrete reactor vessels have necessitated a thorough investigation of the existing failure criteria. In the vessel, because of variations in loading conditions, the principal stresses at any time at any point may vary from biaxial and triaxial compression to compression-tension-tension in any form of combination. These instant changes

Paper published: Proc. Instn Civ. Engrs, Part 2, 1976, 61, Mar., 59-88. 


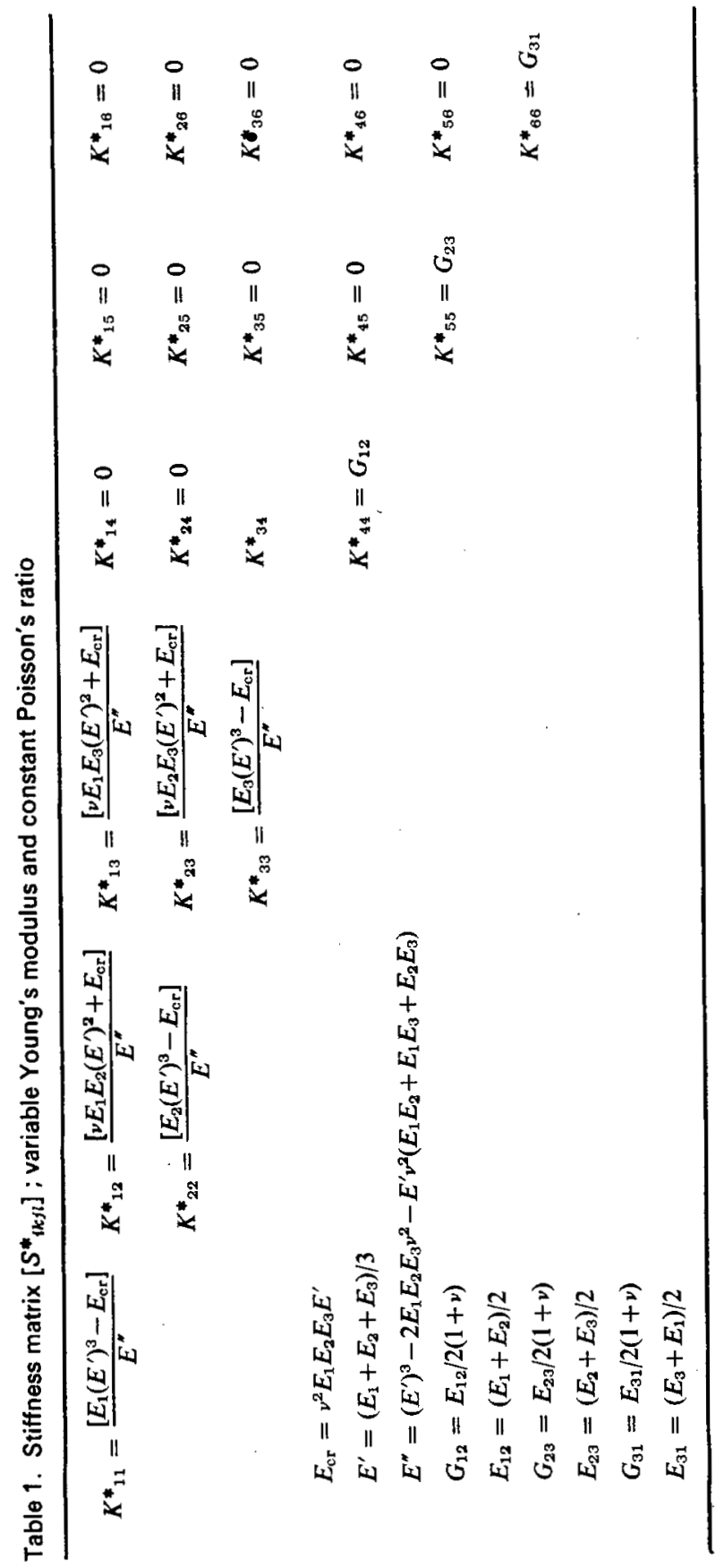




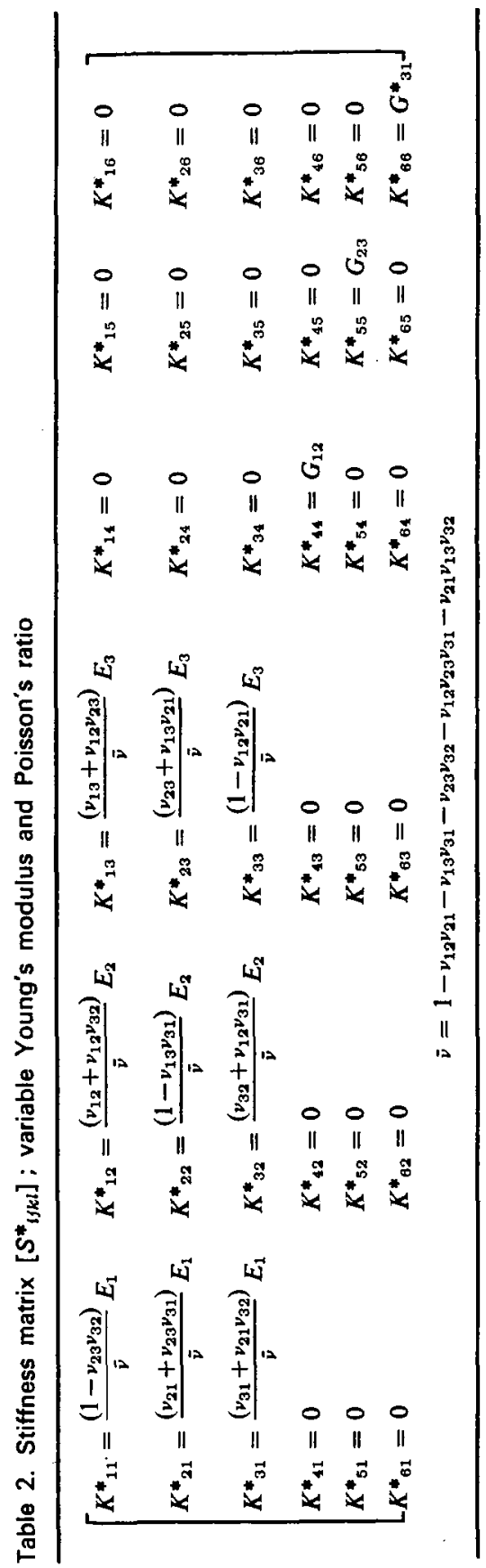


in the principal stress profile which are also dependent on temperature, creep, bond-slip and dowel action are of prime importance and therefore they cannot be ignored, particularly in the overall behaviour of the vessel concrete. Moreover, a typical assumed failure envelope is not the answer for the concrete strength and cracking criteria of the vessel. An alternative approach may be based on the concept of hypo-elasticity.

86. The hypo-elastic concrete element can undergo softening or hardening in strain but at the same time has neither preferred state nor preferred stress and its response to deformation is smooth and gradual. This also means that no failure surface is initially assumed. If the behaviour of the material is judged under large strains, large rotations and abrupt stress changes then the constitutive equations of Truesdell ${ }^{28}$ and $\mathrm{Green}^{28,30}$ will be subject to certain additional restrictions in which the material behaviour in terms of rate of stress can be expressed as a tensor function of stress and rate of deformation. Hence equation (1) can be written in a combined tensor form in three dimensions as

$$
\mathrm{f}(\{\boldsymbol{\sigma}\},\{\boldsymbol{\epsilon}\},\{\dot{\sigma}\},\{\dot{\epsilon}\})=\mathbf{0}
$$

The dots represent the scalar parameters. Comparing this with the incremental stress $\mathbf{d}\{\boldsymbol{\sigma}\}$ in equation (4), it may be given in tri-linear relationship as

$$
\begin{aligned}
d \sigma_{i j}=\mathrm{D}_{\mathrm{T}}\left(\sigma_{i j}\right) \mathrm{d} \epsilon_{k l} & . \\
\mathrm{D}_{\mathrm{T}}= & \mathbf{S}_{i j k l} \text { material property tensor } \\
= & \left(A_{01}+A_{11} \sigma_{\mathrm{rr}}\right) \delta_{i j} \delta_{k l}+\frac{1}{2}\left(A_{02}-2 A_{11} \sigma_{\mathrm{rr}}\right)\left(\delta_{i k} \delta_{j l}-\delta_{j k} \delta_{l i}\right) \\
& +A_{13}\left(\sigma_{i j} \delta_{k l}+\sigma_{k l} \delta_{i j}\right)+\frac{1}{2} A_{14}\left(\sigma_{j k} \delta_{i l}+\sigma_{j l} \delta_{k t}+\sigma_{i k} \delta_{l j}+\sigma_{i l} \delta_{k j}\right)
\end{aligned}
$$

where $\delta$ is Kronecker delta.

87. Various hypo-hydrostatic constants $A$ given in equation ( $39 \mathrm{~b}$ ) have been discussed by Evans and Pister ${ }^{31}$ for any initial stress state for which the incremental deformation is required. The determinant of the tensor stiffness matrix [ $\left.S_{i j k l}\right]$ which has twelve coefficients can be then written as

$$
K_{11}=A_{01}+A_{02}-A_{11} J_{1}+2\left(A_{13}+A_{14}\right) \sigma_{1}
$$

$K_{22}$ and $K_{33}$ have all the terms of $K_{11}$ except that $\sigma_{1}$ is changed to $\sigma_{2}$ and $\sigma_{3}$ respectively.

$$
\begin{aligned}
& K_{44}=\left(A_{02}-2 A_{11} J_{1}\right)+A_{14}\left(J_{1}-\sigma_{1}\right) \\
& K_{55}=\left(A_{02}-2 A_{11} J_{1}\right)+A_{14}\left(J_{1}-\sigma_{2}\right) \\
& K_{66}=\left(A_{02}-2 A_{11} J_{1}\right)+A_{14}\left(J_{1}-\sigma_{3}\right) \\
& K_{12}=\left(A_{01}+A_{11} J_{1}\right)+A_{13}\left(\sigma_{1}+\sigma_{2}\right)=\bar{K}+A_{13}\left(\sigma_{1}+\sigma_{2}\right) \\
& K_{13}=\bar{K}+A_{13}\left(\sigma_{1}+\sigma_{3}\right) \\
& K_{21}=\bar{K}+A_{13}\left(\sigma_{2}+\sigma_{1}\right) \\
& K_{23}=\bar{K}+A_{13}\left(\sigma_{2}+\sigma_{3}\right) \\
& K_{31}=\bar{K}+A_{13}\left(\sigma_{3}+\sigma_{1}\right) \\
& K_{32}=\bar{K}+A_{13}\left(\sigma_{3}+\sigma_{2}\right)
\end{aligned}
$$

where $J_{1}$ is the first invariant of stress.

88. On expansion this determinant gives a geometrical surface in the principal stress space; the second and the third invariants of stress are included in this expansion. For an isotropic case this will give two shapes of pyramidal type. Using appropriate experimental values for various invariants of stress such as those given by Argyris et al., ${ }^{32}$ William et al. ${ }^{33}$ and Launay et al., ${ }^{34}$ the incremental plastic stress-strain criterion, the increment of strain along the strain path and shear can be derived as

$$
\begin{aligned}
& \frac{\mathrm{d} \epsilon p_{2}}{\mathrm{~d} \epsilon p_{3}}=\frac{-K_{11} K_{23}+K_{21} K_{13}}{K_{12} K_{23}-K_{22} \bar{K}_{13}} \quad \text {, . . . . . . } \\
& \frac{\mathrm{d} \epsilon p_{1}}{\mathrm{~d} \epsilon p_{3}}=\frac{-K_{12} K_{21}+K_{11} K_{22}}{K_{12} K_{23}-K_{22} K_{13}}
\end{aligned}
$$


and say for $\sigma_{3}>\sigma_{1}$ or $\sigma_{2}$

$\frac{\mathrm{d} \sigma_{3}}{\mathrm{~d} \epsilon_{3}}=\frac{\begin{array}{c}\left\{\left(A_{01}+A_{02}\right)+\left(-A_{11}+2 A_{13}+2 A_{14}\right) \sigma_{3}-2 A_{11} \sigma_{1}\left[A_{01}+\frac{1}{2} A_{02}+\left(2 A_{13}+A_{14}\right) \sigma_{1}\right]\right. \\ \left.-\left[A_{01}+\left(A_{11}+A_{13}\right) \sigma_{3}+\left(2 A_{11}+A_{13}\right) \sigma_{1}\right]^{2}\right\}\end{array}}{A_{01}+\frac{1}{2} A_{02}+\left(2 A_{13}+A_{14}\right)}$

89. The inclination of the strain path for $d \epsilon$ is given as

$$
\mathrm{d} a^{\prime}=\tan ^{-1} \frac{1}{\sqrt{ } 3} \frac{\left(\mathrm{d} \epsilon p_{1}-\mathrm{d} \epsilon p_{2}\right)+\left(\mathrm{d} \epsilon p_{1}-\mathrm{d} \epsilon p_{3}\right)}{\left(\mathrm{d} \epsilon p_{2}-\mathrm{d} \epsilon p_{3}\right)} \quad . \quad .
$$

$\tau^{*}$ (say $\sigma_{3}-\sigma_{1}$ region) will at any instant become

$$
\tau^{*}=\frac{\left(\sigma_{3}-\sigma_{1}\right)}{\left(\mathrm{d} \sigma_{3} / \mathrm{d} \sigma_{1}\right)+1} \sqrt{\left(\frac{\mathrm{d} \sigma_{3}}{\mathrm{~d} \sigma_{1}}\right)} \quad . \quad . \quad . \quad . \quad . .
$$

90. Equation (41c) also gives material instability at any stage-a concept that could not be achieved by triaxial tests previously.

91. Various sensitivity effects can now be included in the theoretical model. From the stress-strain relationship the value of $E$ can be computed which is dependent on temperature, creep and aggregate interface locking as stated in the Paper. These values would be affected by taking into consideration a constant or a variable Poisson's ratio.

92. Long-term creep values have been determined by extrapolating short-term tests by Hannant ${ }^{35}$ and Browne, ${ }^{36}$ Nasser and Neville, ${ }^{37}$ Launay and Gachon ${ }^{38}$ and Kasami et al. $^{39}$ The values of $E$ have been modified for various temperature regions under operating and hot shutdown cases. The current values of $E$ are then simulated into the matrix [ $\left.S_{y j k l}\right]$. Table 1 gives this matrix when the Young's modulus varies and Poisson's ratio is constant. Table 2 gives the same matrix using variation of Young's modulus with variable Poisson's ratio. Tables 1 and 2 are valid when the principal axes coincide with the reference axes. In the case when they do not coincide with each other, the visual transformation laws of tensors are applied using the angle of orientation $\gamma^{\prime}$ and direction $\operatorname{cosines} c=\cos \gamma^{\prime}$ and $s=\sin \gamma^{\prime}$; the new stresses and strains are then computed

$$
\begin{aligned}
& \left\{\sigma_{x}\right\}=[T]\left\{\sigma_{1}\right\} \quad . \quad . \quad . \quad . \quad . \quad . \quad . \quad . \\
& \left\{\epsilon_{x}\right\}=[T]\left\{\epsilon_{1}\right\} \\
& \left\{\sigma_{x}\right\}=[T]\left[S^{*}{ }_{i j k l}\right][T]^{-1}\left\{\epsilon_{x}\right\} \quad \text {. . . . . . . }
\end{aligned}
$$

where the $6 \times 6$ transformation matrix [T] is as given in Table 3 .

93. Based on this approach various vessels have been analysed for operational and hot shutdown conditions and concrete failure, and their dependent parameters have been reported. ${ }^{40}$ Using mixed elements multi-stage solutions have been carried out using this approach which includes non-linear material properties and non-linear bond-slip

Table 3. Transformation matrix $T$

$$
[T]=\left[\begin{array}{cccccc}
c^{2} & s^{2} & 0 & -2 c s & 0 & 0 \\
s^{2} & c^{2} & 0 & 2 c s & 0 & 0 \\
0 & 0 & 1 & 0 & 0 & 0 \\
c s & -c s & 0 & c^{2}-s^{2} & 0 & 0 \\
0 & 0 & 0 & 0 & c & -s \\
0 & 0 & 0 & 0 & s & c
\end{array}\right]
$$


properties and it has been shown ${ }^{41.42}$ how much flexibility exists in the hypo-elastic approach and how much deficiency exists in the octahedral concept presented by the Authors in which bond-slip cannot be taken into consideration in a single constitutive law. Although the Authors have presented for the plane stress-strain relationship the matrix $\left[D_{\mathrm{T}}\right]^{*}$ in the crack direction in equation $(30)$, their constitutive law does not give the same matrix $\left[S^{*} t_{k}\right]=\left[D_{\mathrm{T}}\right]^{*}$ for the three-dimensional case such as that shown in Tables 1 and 2. Cracking effects are not included in Tables 1 and 2 but, making some of the terms zero for conditions stated in Table 3 and Fig. 14 and assuming that stresses

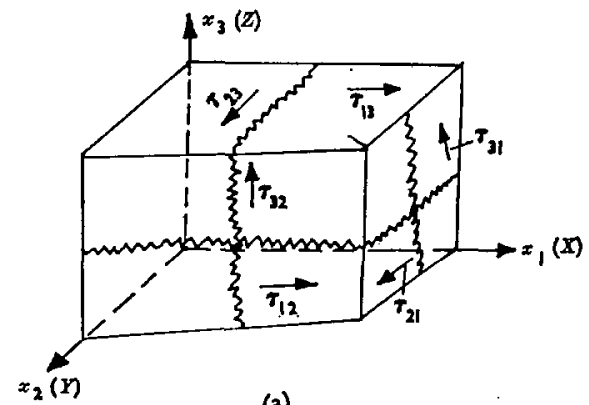

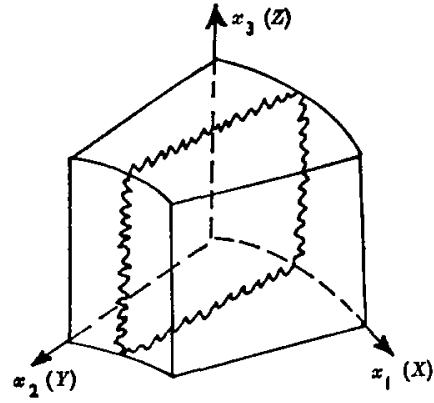

(b)

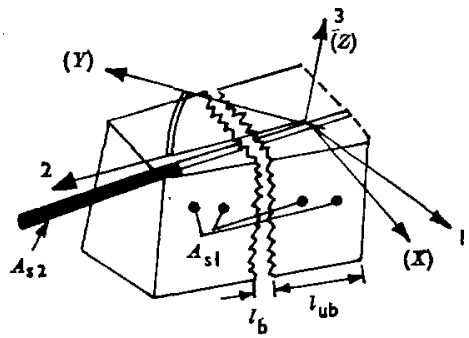

(d) (a)

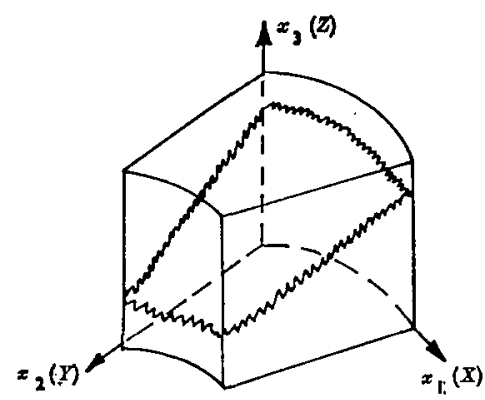

(c)

$$
\begin{aligned}
& X, Y, Z \text { Global co-ordinates } \\
& \text { 1,2,3 Principal axes } \\
& \boldsymbol{B}_{s}=\frac{l_{b}}{l_{b}+l_{u b}} \\
& \text { where } l_{\mathrm{b}} \text { and } l_{\mathrm{ub}} \text { are bonded } \\
& \text { and unbonded lengths }
\end{aligned}
$$

Fig. 14. Crack propagation; (a) general cracking pattern with shear across and perpendicular to cracks, (b) radial crack, (c) circumferential crack, (d) reinforcement and cracks 
Table 4. Tensile stress-strain and cracking criteria to be substituted in matrix $\left[S^{*}{ }_{1 j k}\right]$

Initial tangent modulus in tension: $E_{0}=\left(\frac{\mathrm{d} \sigma_{3}}{\mathrm{~d} \epsilon_{3}}\right)_{\sigma_{1}, \sigma_{2}}$

Tensile strength: $\sigma_{3} \leq \sigma_{\mathrm{t}}+\theta_{\mathrm{s}} \sigma_{1}$

$\sigma_{\mathrm{t}}$ maximum tensile stress

$\theta_{\mathrm{a}}$ slope of cracking envelope

From Fig. 14

Crack in $\sigma_{1}$ direction $K^{*}{ }_{11}=K^{*}{ }_{13}=K_{13}^{*}=0$

Crack in $\sigma_{3}$ direction $K^{*}{ }_{12}=K^{*} 29=K^{*}{ }_{23}=0$

Crack in $\sigma_{3}$ direction $K^{*}{ }_{13}=K^{* 3}=K^{*}{ }_{33}=0$

$K_{44}$ or $K_{55}$ or $K_{66}=a^{\prime} G^{*}{ }_{00}$ for all cases

$G^{*}$ co respective shear moduli in Table 5

Crack at any inclination is defined by equation ( $41 \mathrm{~d}$ )

Table 5. Composite shear moduli $G^{*}$ (concrete modulus + steel modulus)

\begin{tabular}{c|c|c}
\hline Shear modulus & Concrete & Steel \\
\hline $2 G^{*}{ }_{12}$ & $\left(1-B_{\mathrm{s} 1}\right) \frac{E_{\mathrm{c} 1}}{2\left(1+\nu_{21}\right)}+\left(1-B_{\mathrm{s} 2}\right) \frac{E_{\mathrm{c} 2}}{2\left(1+\nu_{13}\right)}$ & $G_{\mathrm{s}}\left(A_{\mathrm{s} 1}+A_{\mathrm{s} 2}\right)$ \\
\hline $2 G^{*}{ }_{23}$ & $\left(1-B_{\mathrm{s} 2}\right) \frac{E_{\mathrm{c} 2}}{2\left(1+\nu_{23}\right)}+\left(1-B_{\mathrm{s} 3}\right) \frac{E_{\mathrm{c} 3}}{2\left(1+\nu_{32}\right)}$ & $G_{\mathrm{s}}\left(A_{\mathrm{s} 2}+A_{\mathrm{s} 3}\right)$ \\
\hline $2 G^{*}{ }_{31}$ & $\left(1+B_{\mathrm{s} 3}\right) \frac{E_{\mathrm{os}}}{2\left(1+\nu_{31}\right)}+\left(1-B_{\mathrm{s} 1}\right) \frac{E_{\mathrm{c} 1}}{2\left(1+\nu_{13}\right)}$ & $G_{\mathrm{s}}\left(A_{\mathrm{s} 3}+A_{\mathrm{s} 1}\right)$ \\
\hline
\end{tabular}

$G_{s}=E_{s} /\left[2\left(1+v_{s}\right)\right]$

$B$, bond-slip

$\nu_{s}$ Poisson's ratio for steel
$E_{c}$ concrete modulus

Subscripts 1, 2 and 3 represent principal stress directions

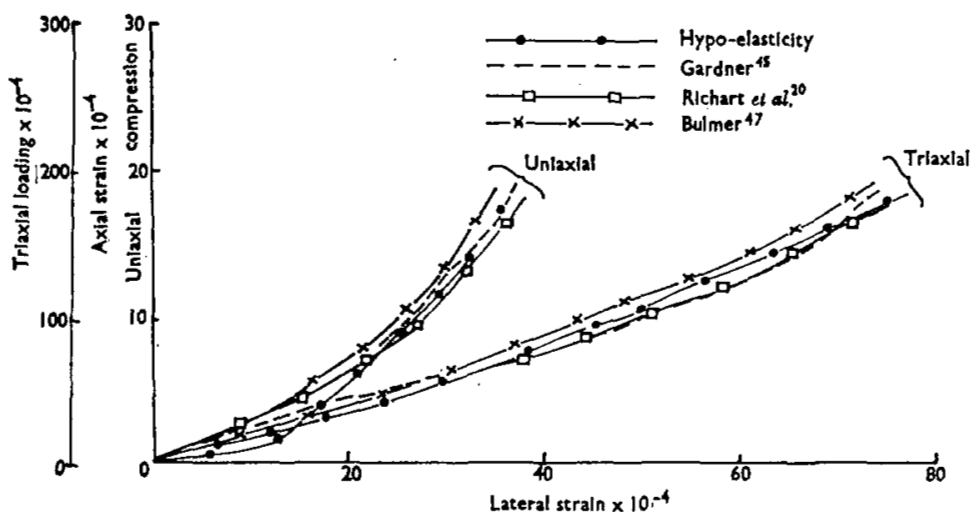

Fig. 15. Axial strain plotted against lateral strain 
DISCUSSION

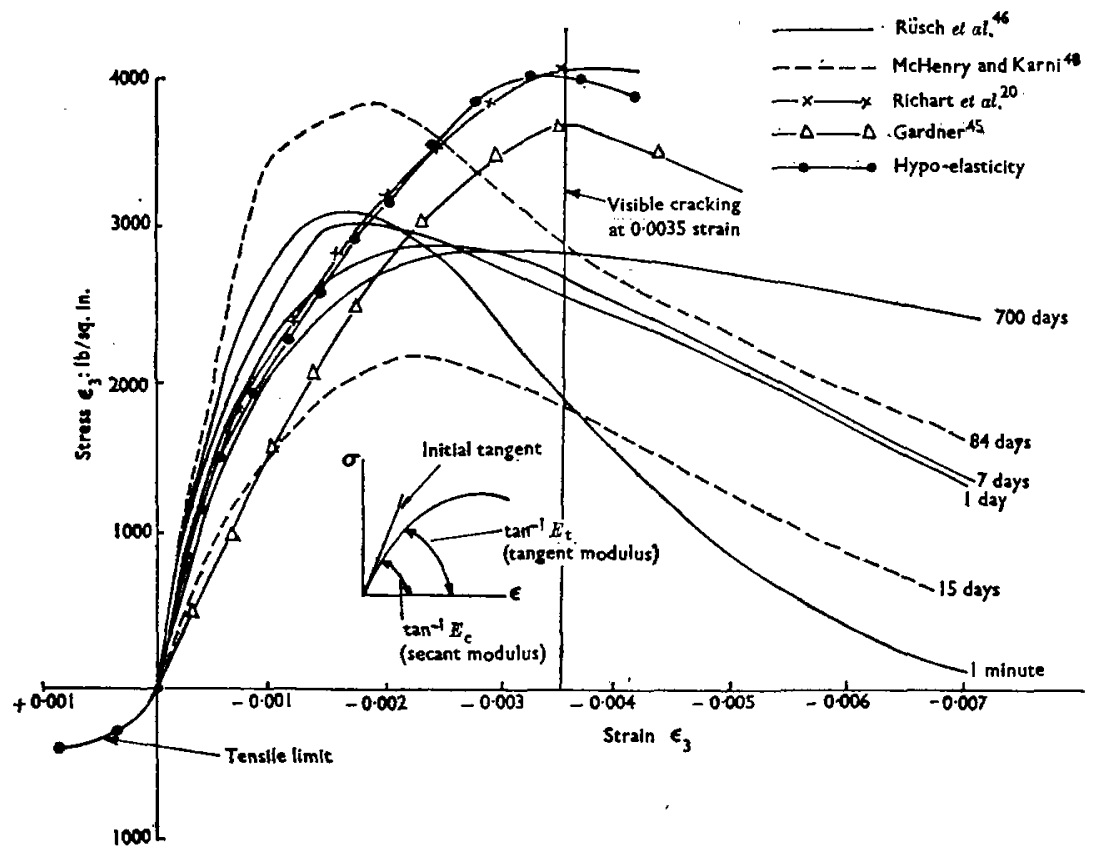

Fig. 16. Stress-strain curve for concrete

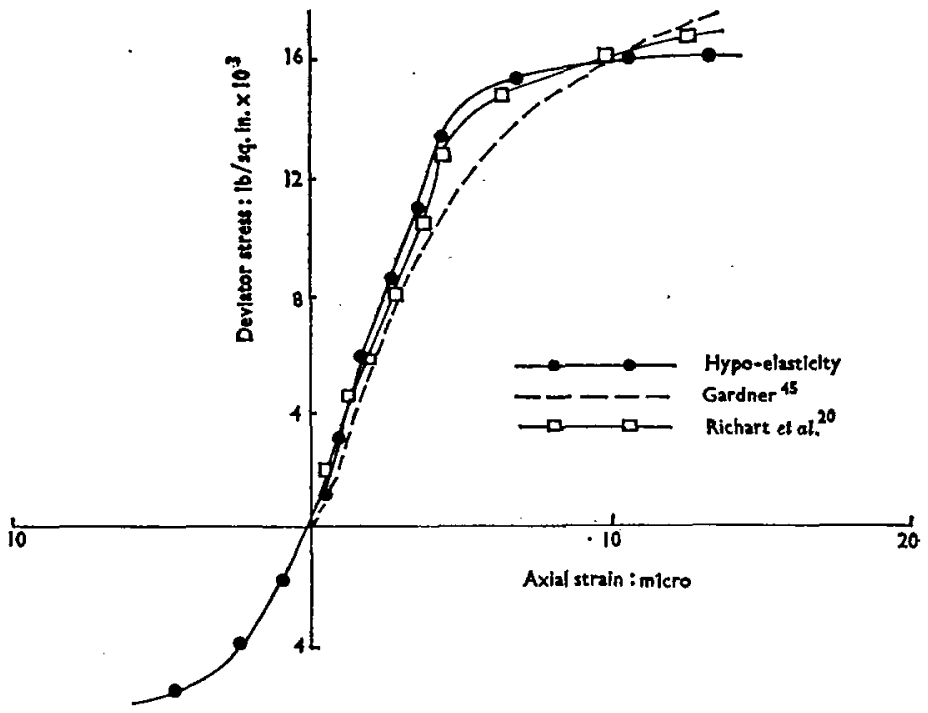

Fig. 17. Deviator stress plotted against axial strain 
and materials laws are adjusted in zones where cracks occur, Tables 1 and 2 suggest a marked improvement on equation (30). The criterion I have chosen is given in Table 4.

94. I agree that little information is available on the differential movement and I accept the Authors' equations (27) and (28). The value of $\tau^{*}$ can be computed from equation (41e). My computer output was based on a three-dimensional isoparametric 32 noded element suggested by Zienkiewic $z^{43}$ and I obtained a series of values of $a^{\prime}$ for various aggregates suggested by Campbell-Allen. ${ }^{44}$ The values for $G$ are based on the composite effect given in Table 5. Most of these values of $a^{\prime}$ are in the range $0.65-0.87$ and are nowhere near to a value of 1 as assumed by the Authors. By introducing the composite values of $E$ and $G$ in Tables 1 and 2, stresses are improved by $10-15 \%$, but this improvement cannot be achieved from equation (30).

95. The Authors have compared their work in Figs 3 and 4 with those of others. 1 am surprised that their results are in close agreement with those of Kupfer et al. ${ }^{18}$ and Richart et $a .^{20}$ despite the Authors' claim that the triaxial study by Richart et al. suffers from testing deficiency of ignoring lateral strain measurements. To what do the Authors attribute this coincidence? Using the three-dimensional criterion on the lines I suggest and adopting data from existing vessels ${ }^{40}$ and from Launay et al., ${ }^{38}$ I obtain different results as shown in Figs 15-18 from those of research workers on isolated

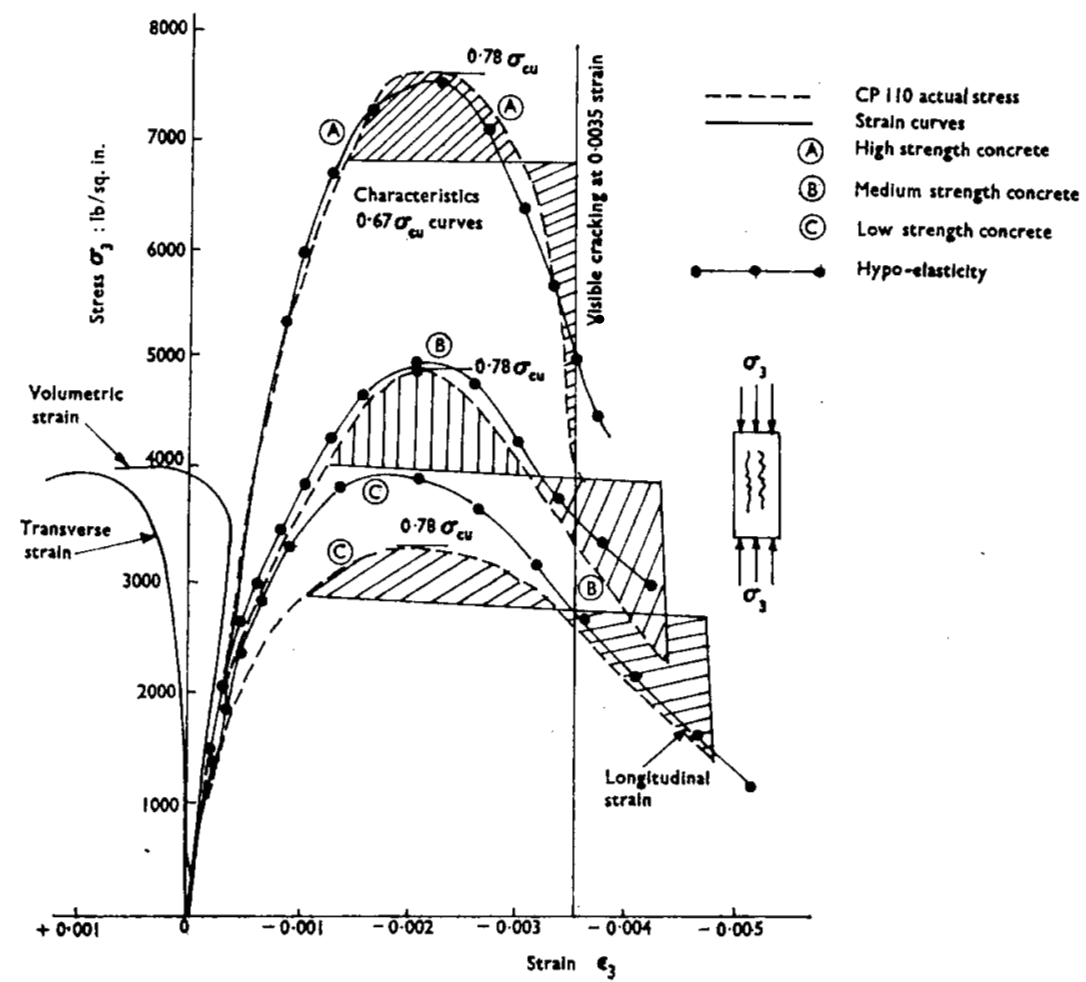

Fig. 18. Typical stress-strain curves for concrete compression; comparison with CP 110 
concrete specimens. ${ }^{45-48}$ In fact there is a difference between the actual behaviour of concrete in the vessel under various loading conditions and that of artificially simulated isolated specimens.

\section{Professor Zienkiewicz and Dr Phillips}

Mr Davidson has highlighted some advantages to be gained by using a dynamic relaxation process, particularly in crack simulation. The technique used in the Paper does not give precise data on crack width and extent because numerically the whole region is assumed to be fissured in a given direction, the stiffness perpendicular to this direction being reduced to negligible values. The position of a single crack has to be interpolated. However, when cracks initiate and propagate, the released loads are shed to adjacent material. The stresses calculated in these regions will have a definite meaning and the changing structural response can be traced from this data.

97. The question of adapting fracture mechanics criteria to mass concrete is an open one. The presence of numerous crack initiators in a uniform distribution gives some meaning to the presence of a maximum (tensile) stress criterion as a starting point of fracture. Beyond this point both the procedure suggested by Mr Davidson and the one described in the Paper lead to the same criteria for further propagation. The important feature in such structures is whether the crack progression is ultimately arrested. The whole field cracking assumption is useful in this context as it clearly indicates the presence (or absence) of such arrest which may be missed if only a single crack is considered.

98. Dr Bangash has presented the concept of hypo-elasticity as a means of handling the constitutive and failure relationships for reinforced concrete, and questioned our omission of temperature, creep, bond-slip and dowel action effects. These are often significant, particularly in the complex conditions imposed on concrete reactor vessels, and in such cases relationships along the lines indicated by Dr Bangash would be useful. However, we were concerned with short-term loading and maintain that in many instances the importance of these effects is small compared with the non-linearities included in the Paper, particularly cracking. Indeed, it was observed that a satisfactory overall analysis up to the useful limits of a structure could sometimes be obtained from a study of tensile crack formation alone. Greater sophistication is often unnecessary and the more simple and convenient laws suggested in the Paper would be sufficient for engineering purposes.

99. We found that it was usually tensile cracking which caused numerical difficulties in obtaining a satisfactory, economic solution. Some of these were indicated in the Paper, e.g. slow convergence rates, the choice of solution techniques and/or accelerating processes, and instability of iterative solutions. Certain guidelines were suggested and it was shown that isoparametric elements were very adaptable in this environment. It is unfortunate that as yet Dr Bangash has not included cracking effects.

100. We were interested in the values of 0.65-0.87 obtained for $a^{\prime}$ by Dr Bangash. Numerical tests on the influence of $a^{\prime}$ on the behaviour of structures showed that its value had small effect provided it was made different from zero. It is clear that more experimentation is needed to obtain good values for $a^{\prime}$ or to replace it by a more realistic expression. For the examples presented in the Paper a value of 0.5 was selected. The value of 1.0 was used for $a^{\prime \prime}$ on the closing cracks so that the material regained its former integrity, except that the tensile strength was removed to cater for the crack opening again at a later stage.

101. The results coincide in Fig. 3 only where the law is applicable, i.e. up to ultimate stress. The strain softening portions of Kupfer's curves are not accurately reproduced because of deficiencies in the law governing behaviour after peak stress. The main approximation was in finding the mean curves of volume change against mean stress and octahedral stress against octahedral strain from the different stress states in a particular concrete. The deviation from the mean curves was small except in the ragion of peak 
stress and after. The laws relating the stress invariants to the tangent moduli were obtained from these mean curves.

102. The purpose of Fig. 3 was to show that the reverse process of using the invariant relationships would compare satisfactorily with the original curves, confirming the basic approach. The results are dependent to a certain extent on the correction factor $c^{\prime}$, which experience indicated should be approximately 0.6 for most of the curves examined. Hence, it is not surprising that the results coincide well before stress, although it is agreed that those of Richart's were better than expected because it has been necessary to assume $K$ constant. We accept that laws derived from tests on isolated concrete specimens under well-defined conditions might not always reproduce the actual behaviour under more complex states of stress found in a structure, but in most cases these tests are the main source of data. Although our work did not indicate that these laws would produce errors, conclusions regarding them were guarded as crack development was usually the main part of the non-linear behaviour.

103. Undoubtedly, much further work is needed in the derivation of laws of concrete behaviour. The non-linear (hypo-)elastic approaches are clearly an approximation as in current work equivalent strain dependent plastic models are being found to yield better description. The fact that in most of the examples excellent agreement with tests was found is an indication that the most important phase of the behaviour and that of tension and cracking response was correctly modelled.

\section{References}

27. Davidson I. The analysis of cracked structures. Trans. 3rd Int. Conf. Struct. Mech. Reactor Technol., 1975, Paper H4/1.

28. Truesdell C. Hypo-elasticity. J. Rat. Mech. Analysis, 1955, 83-133, 1019-1020.

29. Green A. E. Hypo-elasticity and plasticity. Proc. R. Soc., Series A, 1956, 234, 46-57.

30. Green A. E. Hypo-elasticity and plasticity II. J. Rat. Mech. Analysis, 1956, 5, $725-734$.

31. Evans R. J. and Pister K. S. Constitutive equations for a class of non linear elastic solids. Int. J. Solids \& Structs, 1966, 2, 427-445.

32. ARgYris J. H. et al. Recent developments in the finite element analysis of prestressed concrete reactor vessels. Seminar, 1974. International Association for Bridge and Structural Engineering.

33. William K. J. et al. Constitutive model for the triaxial behaviour of concrete. Seminar, 1974. International Association for Bridge and Structural Engineering.

34. Launay P. et al. Déformation et résistance ultime du béton sous étreinte triaxiale. Annls Inst. Tech. Bâtim., 1970, No. 269.

35. Hannant D. J. Creep and creep recovery of concrete subjected to a multiaxial compressive stress. Proc. Am. Concr. Inst., 1969, 66, No. 5, May, 391-394.

36. Browne R. D. Properties of concrete in reactor vessels, In Prestressed concrete pressure vessels. Institution of Civil Engineers, London, 1968, 131-151.

37. Nasser K. and Neville A. M. Creep of concrete at elevated temperatures. Proc. Am. Concr. Inst., 1965, 62, Dec., 1567-1579.

38. LAUnAy P. and GACHON H. Strain and ultimate strength of concrete under triaxial stresses. Proc. Ist Int. Conf. Struct. Mech. Reactor Technol., 1971, 4, Paper H1/3.

39. Kasami H. et al. Properties of concrete exposed to sustained elevated temperature. Trans. 3rd Int. Conf. Struct. Mech. Reactor Technol., 1975, 3, Paper H1/5.

40. BANGASH Y. A basis for the design of bonded reinforcement in the prestressed concrete reactor vessels. Proc. Instn Civ. Engrs, 1972, suppl., xviii.

41. Bangash $Y$. The riddle of bonded and unbonded tendons in prestressed concrete reactor vessels. Concrete, 1974, 8, June, 46-48. 
DISCUSSION

42. BANGASH Y. The theory of movernents in prestressed concrete reactor vessels. Private communication.

43. ZIENKIEWICZ O. C. The finite element method in engineering science. McGrawHill, New York, 1971.

44. CampBell-Allen D. et al. The influence of aggregate on the behaviour of concrete at elevated temperatures. Nucl. Engng \& Des., 1967, 6, 66-77.

45. Gardner N. J. Triaxial behaviour of concrete. Proc. Am. Concr. Inst., 1969, 66, No. 2, Feb., 136-147.

46. Rüsch H. et al. Festigkeit und verformungen von unbewehrtem Beton unter konstanter Dauerlast. Daftst B, 1968, 198.

47. BULMER G. G. Shearing strength of concrete under high triaxial stress computation of Mohr's envelope as a curve. U.S. Department of the Interior, 1949, LR SP-23, 1-19.

48. MCHenry D. and Karni J. Strength of concrete under combined tensile and compressive stress. Proc. Am. Concr. Inst., 1958, 54, No. 10, Apr., 829-840. 